\title{
The role of specialisation and diversity externalities in the agglomeration of innovative activities
}

\author{
Raffaele Paci \\ University of Cagliari and CRENoS \\ paci@unica.it \\ and \\ Stefano Usai \\ University of Sassari and CRENoS \\ usai@uniss.it
}

\begin{abstract}
This paper contributes to the analysis of the process of spatial agglomeration of innovative activities by investigating directly its determinants. Our main purpose is to identify the extent to which the degree of industrial specialisation (Marshall externalities) or diversity (Jacobs externalities) in the region may affect the innovative output in a particular local industry. Moreover, we test if any relevant difference arises with respect to the role of diversity in metropolitan areas and in high-tech sectors. The analysis is carried out thanks to an original databank on innovation and production across Italian local labour systems.

According to the estimation results there are clear signs of the two types of externalities working simultaneously: Marshall externalities (or localisation economies), associated to industrial specialisation within the sector and also within the science base cluster; and Jacobs externalities (or urbanisation economies), associated to the degree of diversity of both the local districts and the science base cluster. With respect to the industrial diversity at the local district level, however, it is worth noting that it plays a different role depending on the dimension of the local district (whether it is a metropolitan area or not) and on the type of industry (high Vs low tech sectors).
\end{abstract}

JEL: O31, O18, R12

Keywords: Innovation, Industrial agglomeration, Externalities, Geography, Italy. 


\section{Introduction *}

Why specific productive activities are geographically concentrated is a question which is still to find a completely persuasive answer, even though it has been on the forefront of economists' debate in the past [Marshall (1890) and Weber (1909)] and in more recent times [Romer (1986), Arthur (1988), Krugman (1991), Lucas (1993) among others]. Other similar puzzles, probably less investigated in the past, arise with respect to the agglomeration process of technological activities and its relationship with the spatial distribution of production. In recent years, however, there has been an interesting upsurge in this stream of literature. This is confirmed by the latest empirical contributions within the new economic geography approach [Feldman and Audretsch (1999) and Kelly and Hageman (1999) for the USA case; Breschi (1997), Paci and Usai (1999) and Caniels (1999) for the European one] and by the regional economics literature (see, for instance, the 1999 special issue of Regional Studies on "Regional networking, collective learning and innovation").

A useful starting point of the analysis is the acknowledgement that the pattern of spatial agglomeration of innovative activities is mostly related to the process of knowledge creation and diffusion. It is argued that such a process is still influenced by the economic, social and institutional features of the place where the firm is located. Such features gradually mould the internal structure and the network of external relationships of each firm. In other words, some knowledge grows embodied in individuals, in the organisation of the firm as well as in the institutional surroundings and, as a result, becomes spatially bounded and difficult to be traded or to be moved from one location to another.

Two types of externalities are usually recognised to play a major role in the process of knowledge creation and diffusion: specialisation economies [Marshall (1890)] which operate mainly within a specific industry and diversity economies [Jacobs (1969)] which are at work across sectors. On the one hand, Marshall observes that industries specialise geographically because proximity favours the intra-industry transmission of knowledge. On the other hand, Jacobs (1969) believes in diversity as the major engine for fruitful spillovers and innovations given that "the greater the sheer number of and variety of division of labor, the greater the economy's inherent capacity for adding still more kinds of goods and services" (p. 59).

The aim of this paper is to contribute to the analysis of the process of spatial localisation of innovative activities by investigating directly its main determinants and, more specifically, the controversial role of industrial variety and specialisation. Further, we explore the role of

\footnotetext{
* We would like to thank Mario Paffi for valuable research assistance and Ernesto Batteta, Graziella Sulis and Paola Zinzula for their excellent work in the set up of the database. We thank David Audretsch, Ron Borschma, John Cantwell and Bart Verspagen for helpful suggestions. We have also benefited from comments by participants to ERSA 1999 Conference and CRENoS $4^{\text {th }}$ Conference. Financial support by MURST and CNR is gratefully acknowledged.
} 
complementary industries, which share the same science base, in terms of their degree of both specialisation and diversity. Finally, we test whether there is any significant difference in the impact of Jacobs externalities with respect to the dimension of cities and the propensity to innovate of the sectors involved.

The empirical application refers to the case of Italy, which proves particularly appropriate because a salient feature of the Italian economy is the presence of several production systems [see Becattini (1987)] which represents an almost ideal spatial unit to analyse the interaction between innovative and productive activities. More exactly, the geographical level used in this paper - called Local Labour System (LLS) - represents a grouping of municipalities characterised by a high degree of self-contained flows of commuting workers. Our data on the production activity (number of employees and firms) for 784 LLS are from the Italian Statistical Office (ISTAT). The information on innovative activity has been collected by CRENoS from the EPIDOS databank on patenting at the European Patent Office (EPO). We have thus assigned the innovations to the local labour systems on the basis of the inventors' residence. As far as the sectoral split is concerned, our patents data are defined for three-digit sectors thanks to the Yale technological concordance which allows to transform the International Patent Classification (IPC) into a classification referred to the industry of manufacture. The result of the merge of these two databases is a particularly rich and potentially fruitful set of information on both production and innovation which allows for a very detailed spatial and sectoral analysis of the agglomeration process.

The structure of the paper is as follows. In section 2, we discuss the main theories concerning the nature of localised technological spillovers. Section 3 presents the main features of our data base on innovative activity in Italy and examines the degree of specialisation and diversity across local labour systems and industrial sectors. Section 4 sketches the theoretical model to be estimated. The econometric estimates of the determinants of the geographical distribution of innovative activity are presented in section 5. Finally, concluding remarks together with some suggestions for future research are provided in section 6.

\section{Background literature}

The debate on the existence of various forms of agglomeration economies is a long and rich one, as we have already stressed in the Introduction. Most contributions are based on the belief that there exist self reinforcing mechanisms - that is, increasing returns - which are spatially bounded. ${ }^{1}$

\footnotetext{
1 There may, obviously, be also agglomeration diseconomies due most of all to congestion effects. It should be, however, remarked that such effects are likely when externalities operate through physical infrastructure rather than through knowledge channels, which are central in our research. For simplicity sake, we refer to increasing returns to indicate all those cases when net benefits between economies and diseconomies are positive.
} 
Considering the production side (localisation and pecuniary externalities), such increasing returns can materialise, for example, as an appropriate specialisation and diversification pattern facilitating the provision of specific goods and services according to an input output framework [Bartelsman et al. (1994)]; as a more convenient set of relative prices and qualities of the labour force and of primary and intermediate goods [Ellison and Glaeser (1999)]; or, finally, as a set of useful ad hoc infrastructures.

As regards to technological externalities, local networks may emerge in order to ease the exchange of information and expertise which, despite the great progress in information technologies, are still costly and difficult to transmit across areas [Jaffe et al. (1993), von Hippel (1995)]. ${ }^{2}$ Moreover, local collective learning processes based on tacit knowledge [Lawson and Lorenz (1999), Capello (1999)] may constitute an important basis for the competitive advantages of regions and therefore for their potential attractiveness. In other words, parallel to agglomeration economies, which contribute to the creation of local production systems, there may exist other increasing returns in spatial form which favour the formation of regional innovation districts.

How much these two forms of local systems are related, along which channels they interact (i.e. what is the nature of the externalities) and how they affect local growth are central questions faced, with various methodological approaches, by researchers in the fields of industrial, regional and growth economics [see Ottaviano and Puga (1998) and Brulhart (1998) for updated surveys on the new economic geography literature]. For our purpose it may be useful to distinguish four research directions.

The first direction is represented by the long standing literature on "spatial innovation networks" and "innovative milieu" [Camagni (1991, Cooke and Morgan (1994), Regional Studies (1999, n.4)] and "industrial districts" [Brusco (1982), Pyke et al. (1990)]. This approach usually grounds its research on case studies of specific areas which allow for detailed analyses of the complex interacting forces that shape the development of a local system (i.e. a combination of economic, social and cultural elements).

A second line of research investigates the spatial distribution of innovative activities in larger economic systems and tries to identify common trends and patterns in the clustering of innovation. These studies have analysed USA cities and states [Jaffe et al (1993), Feldman (1994) and Audretsch and Feldman (1996)] and the European regions [Breschi (1997), Caniels (1999), Paci and Usai (1999), Verspagen (1999)]. A substantial effort has been dedicated to the set up of new

\footnotetext{
${ }^{2}$ On the other hand, there is an important stream of the literature [see the seminal work by Coe and Helpman (1995)] which stresses the non rival nature of technological progress. According to this view R\&D spillovers go across borders and may contrast the appearance of spatial patterns of innovative specialisation. In other words, there exist countervailing forces - those ones which facilitate spatial diffusion of knowledge, experience and technologies and those ones which enhance local increasing returns - which are both in action.
} 
databanks on innovation activities, measured by patents applications, patents citations, new products announcements.

The third approach directly assesses the nature and the effects of externalities on the growth process of local systems. The empirical applications have focussed again on the US case [Glaeser $e t$ al. (1992), Henderson et al. (1995), Lamorgese (1997)] and have reached contrasting results on the relative importance of the specialisation and diversity externalities. A common shortcoming in the empirics of these studies is the lack of a specific variable to measure innovation activities, which makes the assessment of the role of technological externalities rather indirect.

The fourth line of research investigates directly on the nature of the spillovers between production and innovation activities through a theoretical framework where the spatial agglomeration of innovation depends, among other factors, on the degree of specialisation of the local production system [Feldman and Audretsch (1999), Kelly and Hageman (1999), respectively on the cities and states of the USA]. The most striking, and probably unexpected, result of both these analyses is that there is no evidence of specialisation externalities. In other words, in the United States innovation in a specific sector exhibits strong spatial clustering independently of the distribution of manufacturing activity in the same sector. Moreover, Feldman and Audretsch (1999) provide some evidence according to which diversity externalities prevail in the case of USA metropolitan areas. Contrary to this result, Paci and Usai (1999) show that in the European regions there exists a positive association between the spatial distribution of technological and productive specialisation, an indirect support to the idea of Marshall externalities.

Following this latest approach, in the present paper we are interested in investigating the nature of knowledge spillovers among the Italian local districts by means of more refined measures and indicators. Consequently, we will be able to assess whether the absence of Marshall externalities in innovation detected for the USA can be generalised to other geographical settings.

\section{Innovative activity in the Italian local districts}

\subsection{Some measurement issues}

Our empirical analysis is based on a new database on innovative activity in the European regions set up by CRENoS [an earlier version is presented in Paci and Usai (1999)]. As an indicator of the innovative activity we use patent applications to the European Patent Office (EPO) from 1978 to $1995^{3}$, classified by inventors' residence. ${ }^{4}$

\footnotetext{
${ }^{3}$ The information set used in this article is however truncated to the period from 1981 to 1994 . The reason is that for the first three years data are distorted since patenting at EPO was a rather rare phenomenon due to the novelty of the system. For the last year delays in the registration procedure make the available information incomplete.

${ }^{4}$ For the case of patents with more than one inventors, we have proportionally assigned a fraction of each patent to the different inventors' city of residence.
} 
There are several issues concerning patent statistics which need some preliminary elucidation. First of all, the choice of patents as a measure of innovative activity is always a controversial one, even though widely used [see, for example, the recent aforementioned paper by Kelly and Hageman (1999)]. We believe that such a measure has several pitfalls, already thoroughly discussed in the literature [Pavitt (1982), Griliches (1990)], and that researchers have to be particularly wary when they use it. However, at a certain level of geographical split there is simply no alternative to patents. Moreover, other potential measures, such as R\&D expenditure or innovation announcements, are not without weaknesses themselves.

There are some additional persuasive considerations in favour of the use of this indicator for the purposes of our analysis. Contrary to other patent indicators, applications at EPO provide a measure which is of a sufficiently homogenous quality, due to the fact that applying to EPO is difficult, time consuming and expensive. Our indicator, in other words, is particularly effective in order to take into account potentially highly remunerative innovations which for this reason are patented abroad. Moreover, it is an indicator for both product and process innovations and, therefore, a more comprehensive measure of the innovative activity for several industrial sectors. Finally, the availability of the whole time series for the years 1978-95 allows to use annual averages in order to avoid the intertemporal oscillations which may not directly be related to technological progress.

Another important feature of our database is the use of the inventor's residence, rather than the proponent's residence, in order to attribute the spatial localisation of each innovation. Indeed, the latter generally corresponds to firms' headquarters and therefore it might underestimate the peripheral regions' innovative activity whenever the invention has been developed in a firm's subsidiary located in another area. ${ }^{5}$ Therefore, the inventors' region of residence provides a more precise measure on the exact geographical origin of the innovative activity.

As far as the sectoral classification is concerned, patent data, originally classified by means of the International Patent Classification (IPC), have been referred to the industry of manufacture thanks to the Yale Technology Concordance ${ }^{6}$ [see in Evenson (1993)]. Such a concordance uses the probability distribution of each IPC or product code across industries of manufacture in order to

\footnotetext{
${ }^{5}$ For instance, the headquarter of Enichem, the Italian petroleum and chemical multinational, is located in Milan (Lombardia) but the innovative activity (as indicated by the residence of the inventors) is much more dispersed due to the presence of several plants in other regions (e.g. Veneto, Sicilia, Liguria and Sardegna).

${ }^{6}$ Conversion tables and detailed explanations on the procedures of the Yale Technology Concordance are provided by Johnson and Evenson at the Internet address (http://www.wellesley.edu/Economics/johnson/jeps/index.html).
} 
attribute each patent proportionally to the different sectors where the innovation may have originated $^{7}$.

As for the geographical unit of analysis, our data refer to Local Labour Systems (LLS) identified by Sforzi (1997). The complex identification procedure of LLS can be summarised in two steps: first, it identifies municipalities which exhibit a relatively high degree of centrality (i.e., they attract a large number of workers who live in near municipalities) and a high degree of selfcontainment (i.e., they have a large share of their resident workforce employed in those same municipalities); secondly, the procedure carries on by aggregating the municipalities with the highest degree of centrality and of self-containment with those close-by municipalities from which work flows originate. Based on the 1991 census data, the Italian Statistical Office has identified 784 LLS.

\subsection{The spatial distribution of innovative activity}

In this section we provide a description of the geographical distribution of innovative activities, that is the dependent variable of the econometric analysis we present in the next sections. A first effective picture of the spatial distribution of the innovative activity across the Italian LLS is presented in Figures 1-4 for the two sub-periods 1981-85 and 1990-94. Figure 1-2 reports the innovative activity in absolute values while patents are divided by population in Figures 3-4.

It is immediately visible that innovation is an extremely dispersed and, in the case of Italy, dualistic phenomenon which divides North and South (see also Table 1). There are other interesting facts worth noting. Let us start examining the dynamics of total patenting by comparing Figure 1 and 2. First of all, one notes that the number of local districts without any patenting activity declines significantly during the decade under exam: from 478 to 369 . The corresponding increase in the number of "innovative" local districts gives rise to an upward shifting of the entire distribution of patenting activity. Significantly, the two most innovative groups (consisting of those local districts with an annual number of patents higher than three) grow from 51 in the eighties to 109 LLS in the nineties. ${ }^{8}$ As regards the spatial distribution of patents per capita (figure 3 and 4), one may note that especially in the early eighties the distribution is even more skewed in favour of the North with respect to the South. Interestingly, there appear some regions with medium-high innovative

\footnotetext{
${ }^{7}$ In practice, this process of conversion allows to translate IPC's into industrial definitions referred to the Italian ATECO classification has been rather complex, given that it has required three consecutive transformations. First, the Yale concordance allowed us to transform the IPC to the Canadian SIC classification; second, the latter has been reverted to the International Standard Industrial Classification rev. 3 (ISIC) thanks to concordance tables supplied by Jon Haveman, at the Internet site (http://intrepid.mgmt.purdue.edu/Trade.Resources/TradeConcordances.html). Finally, ISIC data have been converted into ATECO 91 classification, which is the Italian analogous of ISIC, thanks to a conversion table provided by the Italian Statistical Office (ISTAT).

${ }^{8}$ Note that these 109 LLS represent the geographical sample used for the econometric analysis in section 5.
} 
propensity (those in the range in between 2 and 5 patents per capita which appear grey in the maps) in the Centre. Such a result is confirmed in the nineties in Figure 4, where it is possible to detect some more grey regions in the Adriatic belt. One can also spot some grey districts in the South. However, it should be remarked that, with the notable exception of Catania, the other cases (Fonni, Sant' Arcangelo, Rocca Imperiale and Sant'Angelo le Fratte) appear in this class mostly because of their extremely modest size in terms of population rather than because of their innovative capacity ${ }^{9}$.

This "visual" evidence is substantiated by detailed information in Table 1, where one finds the distribution of innovative activity across four macro regions. About $83 \%$ of the innovations in the early eighties have originated in the North (more exactly, $58 \%$ in the Northwest and $25 \%$ in the Northeast). Only $14 \%$ were located in the Centre and just 3\% in the South and in the Islands. Ten years after, in the early nineties apparently nothing has changed. Only did the Northeast gain almost three percentage points with respect to the Northwest: the former, as a matter of fact, increases up to $27 \%$ and the latter declines to $54 \%$. The quotas for the Centre and the South are quite unaltered. This picture is strengthened when one examines the distribution of patents per capita (last four columns in Table 1). While in the Northwest there were almost 17 patents per 100.000 inhabitants in the early eighties and 40.5 in the early nineties, in the South such an indicator was below one (0.74) in the first period and just above two (2.24) in the more recent period. As one can see from the base indexes such a result is rather constant along time: the North is regularly above 200 (with respect to Italy $=100$ ) while the South moves only slightly from 9.3 to 11.4 . In conclusion there does not appear any clear signal of a catch up process which should close up the innovative gap between North and South of Italy.

In order to get a more adequate indication of the dispersion of the innovative activity across local districts and its evolution along time we have calculated different measures of variability, such as the concentration ratio, the coefficient of variation and the Herfindal index. The dynamics of such indexes prove almost equivalent and therefore in Figure 5 we report only the evolution of the latter indicator. It is clear that there has not being a monotonic trend throughout the years. The concentration is rather erratic in the eighties and tend to decrease quite regularly only in the last years after 1990. As a matter of fact, the 10 most innovative districts used to cover slightly more than half $(52 \%)$ of patent activity in the early eighties but declined to around $45 \%$ in the nineties.

In Table 2 and 3 the twenty five most innovative local districts are listed with respect to total patents and patent per capita respectively. Large cities, such as Milan, Turin, Rome, Bologna and Florence, are the top five innovation centres when one considers the total number of patents (Table 2). Immediately below one finds some important districts of the Northeast, such as Pordenone and

\footnotetext{
${ }^{9}$ It is difficult to find the optimal indicator for innovative activity. We opted for total counts and per capita figures even
} 
Padova. The picture changes widely when we consider the per capita values in Table 3: Pordenone becomes the most innovative district and the second most innovative area is also in the Northeast, Montebelluna. Other small centres which climb in the ranking while passing from total to per capita counting are Sesto Calende, Ivrea and Savona, all districts located in the North, and interestingly Fabriano, a district located in the fast growing Adriatic belt. Among the large cities only Milan and Bologna hold their ranking in the top ten also in Table 3.

Let us now examine the sectoral distribution of technological activity. Table 4 reports the twenty most innovative sectors in terms of total patenting. The top sectors are General purpose machinery, Basic chemicals and Engines and turbines which together collect around $40 \%$ of patents. The ranking appears very stable over time: the top twenty sectors are the same for the eighties (1981-85) and for the nineties (1990-94). The only changes refer to some reshuffle, such as that of Pharmaceuticals, which ascend from the $13^{\text {th }}$ position in the eighties to $4^{\text {th }}$ in the nineties. It is also interesting to note that on average the quota of the top sectors over total patenting increases over time. The quota of the General purpose machinery sector, for example, goes from one fifth of the total in the early eighties to one fourth in the early nineties. In other words patenting across sectors seems to become more and more concentrated along time.

\subsection{Specialisation and diversity}

One of the aims of this paper is to assess the role of specialisation and diversity on the agglomeration of technological activity. It is, therefore, useful to provide a preliminary description of the main features of these indicators across the Italian local systems. Table 5 and 6 report the specialisation and diversity indexes for the twenty five most innovative districts (in terms of total patents) for production and innovation activities respectively. The specialisation index, which can be used as a proxy for Marshall externalities, is computed by means of a standardised comparative advantage index. As an indicator for the degree of diversification among sectors - that is for Jacobs externalities - we use the reciprocal of the Gini concentration coefficient. Both indexes are fully described in section 4 .

The first impression is that the phenomenon under study is rather complex and heterogeneous. For instance, as regards the specialisation measure, there appear some unexpected results, such as the specialisation of Rome in the production of television and radio transmitters or of Turin in the innovation activity of prepared animal feeds (even though the second highest specialisation index is for motor vehicles). At the same time, it is possible to spot some unsurprising 
specialisation patterns, such as that of Florence in the manufacture of luggage and handbags or that of the district of Milan for innovation in the publishing sector.

It is also possible to detect a few general regularities. First of all, diversification is always higher in production than in innovation, which proves a less dispersed phenomenon. A second interesting, although expected, result is that the highest degree of variety, both in production and innovation, is found in large cities. Milan, Bologna, Florence, Rome and Varese show very high values of the diversity index. On the other hand, the highest sectoral concentration is detected in the industrial districts. For instance, the lowest degree of production diversification (0.15) is displayed by the district of Ivrea, not surprisingly a centre for the manufacture of computers and office machinery dominated by Olivetti ${ }^{10}$. Other examples of highly specialised local districts are Montebelluna for footwear and sport goods and headquarter of famous brand-name firms such as Nordika and Dolomite and Pordenone specialised in television and domestic appliances thanks to the presence of Zanussi and Seleco.

In the next sections we attempt to include some of these features into a modelling framework of the localisation of the innovative activities.

\section{The modelling framework}

To evaluate the effects of industrial specialisation and diversity on the agglomeration of innovative activities we estimate a simple model where the dependent variable $\mathrm{y}_{\mathrm{ij}}$, i.e. the level of innovative activity in sector $i$ and local labour systems $j$, depends on three vectors of explanatory variables representing local industries characteristics $\left(x_{i j}\right)$ and some other specific features of either the local districts $\left(z_{j}\right)$ or the industrial sector $\left(s_{i}\right)$. Thus we have:

$$
\mathrm{y}_{\mathrm{ij}}=f\left(\mathbf{x}_{\mathrm{ij}}, \mathbf{z}_{\mathrm{j},} \mathbf{s}_{\mathrm{i}}\right)
$$

Among the first set of variables specific to each local industry $\left(x_{i j}\right)$, we include, first of all, a production specialisation index (PS) based on employment data $(E)$ :

$$
P S_{i j}=\left[E_{i j} / \sum_{i} E_{i j}\right] /\left[\sum_{j}^{\left.\sum_{i j} / \sum_{i} \sum_{j} E_{i j}\right]}\right.
$$

This index represents the usual measure for Marshall externalities. As a result, a positive and significant sign of its coefficient is interpreted as evidence of the fact that innovations are bound to arise within those sectors in which the production of local districts is specialised. For the empirical

\footnotetext{
${ }^{10}$ From a dynamic point of view Ivrea is particularly interesting given that there appears a clear drop in its innovation capacity, associated to the crisis of Olivetti, during the late eighties and early nineties.
} 
analysis the index has been standardised using the formula (PS-1)/(PS+1), so that it is constrained within the interval $(-1,1)$.

Moreover, following Feldman and Audretsch (1999) ${ }^{11}$, we include a science base specialisation index (SBS), again based on employment data, as an indicator of the degree of specialisation of the local district across complementary industries which share the same science base with the sector $i$ considered:

$$
S B S_{i j}=\left[E_{i j}^{k} / \sum_{i} E_{i j}\right] /\left[\sum_{j} E_{i j}^{k} / \sum_{i} \sum_{j} E_{i j}\right]
$$

where $E_{i j}^{k}=\sum_{i} E_{i j}^{k}-E_{i j}, k=1 \ldots 6$ and $i \in k$. This index is computed in the standardised form too . Feldman and Audretsch (1999) interpret the positive sign on this coefficient as evidence in favour of diversity externalities given that, according to their argument, such externalities cannot arise outside the common science base cluster. In this paper we test for the presence of Jacobs externalities more directly by assessing the impact of diversity as such, thanks to the indexes PD and SBD described below. As a result, we prefer to read a positive and significant sign of the coefficient of SBS as a further signal of the importance of specialisation (even though in near-by industries) and therefore of Marshall externalities. The six science base clusters considered are Agra-business, Chemical engineering, Office machinery, Industrial machinery, High-tech computing, Biomedical. $^{12}$

As regards to the vector of determinants which are given for each LLS $\left(z_{j}\right)$, our main aim is to measure the degree of variety which characterise each local district. First of all, we include a production diversity index (PD) for the whole local district based on the reciprocal of the Gini coefficient:

$$
P D_{j}=\left[\frac{2}{(n-1) Q_{n}} \sum_{i=1}^{n-1} Q_{i}\right]
$$

where $\mathrm{Q}_{\mathrm{i}}$ is the cumulative sum of employees $(E)$ up to sector $i$ when sectors are listed in increasing order. The index is defined within the interval $(0,1)$ and it increases together with variety. The same formula has been used to construct an innovation diversity index $\left(\mathrm{ID}_{\mathrm{j}}\right)$ where the cumulative sum refers to patents rather than to employees. The index PD allows for testing the Jacobs hypothesis, according to which a higher level of diversification of the local system favours innovative activity.

\footnotetext{
11 There is however an important correction made to the original formula used by Feldman and Audretsch (1999). While calculating the index for the sector $i$ they do not control for the amount of innovative activity of the sector $i$ itself. This is important in order to consider only the effects of the similar industries without replicating the specialisation index above.

${ }^{12}$ We thank David Audretsch for providing the concordance table between industries and science based clusters based on the Yale survey. See Feldman and Audretsch (1999) for details.
} 
Given that the Gini coefficient is a measure of concentration, an increase of its reciprocal implies that diversification is higher. We, thus, interpret a positive, significant sign on its coefficient as evidence of the presence of diversity externalities ${ }^{13}$.

Another interesting dimension of variety at the local district level is given by the degree of diversity within the science base cluster (SBD). The index to measure such a diversity is obviously identified for each local district and each sector (and therefore pertains to the group of the $x$ variables). The formula is, again, based on the reciprocal of the Gini coefficient referred to employment within the sectors which constitute the cluster $k$ defined above.

$$
S B D_{i j}=\left[\frac{2}{\left(n^{k}-1\right) Q_{n}^{k}} \sum_{i=1}^{n^{k}-1} Q_{i}^{k}\right]
$$

where $\mathrm{Q}_{\mathrm{i}}$ is the cumulative sum of employees $(E)$ in cluster $k$ up to sector $i$ when sectors are listed in increasing order. This index allows for a further specification of the degree of diversity in the local district likewise the tests on production specialisation above. In other words, thanks to this variable we are able to assess the role of diversity also among those sectors which, due to the sharing of the same common science base, are likely to cross fertilise themselves more easily. A positive significant sign will be read as a further evidence of the presence of diversity externalities.

Among the $z$ variables, specified for each local districts, we also include a dummy variable for metropolitan areas $(\mathrm{DM})^{14}$. Such a dummy is meant to discriminate between main urban areas and small local districts in order to test whether, as argued by Glaeser et al. (1992), Jacobs externalities are more likely to operate within metropolitan areas, where there coexist many manufacturing sectors.

Finally, we control for explanatory factors specific to each sector by means of the $s$ variables. First of all, we check if the agglomeration process of innovations depends on the level of available knowledge and innovations in each sector, that is the level of technological opportunity (TO). Technological opportunity is computed as:

$$
T O_{i}=\sum_{j} P_{i j}
$$

where $\mathrm{P}_{\mathrm{ij}}$ is the number of patents in sector $i$ and LLS $j$. This index is supposed to provide a measure of the amount of specific knowledge available at the national level for further development and research within a certain sector. We expect a positive sign on its coefficient.

\footnotetext{
${ }^{13}$ In some cases the same index is used to discriminate between Marshall and Jacobs externalities (see for example Lamorgese, 1997, even though in a different setting). This is often due to data availability. We believe that, when this is possible, the two hypotheses should be tested separately with different and more appropriate indicators.

${ }^{14}$ Metropolitan area are defined by ISTAT, and include the following 12 towns with more than 250,000 inhabitants: Turin, Genoa, Milan, Venice, Bologna, Florence, Rome, Naples, Bari, Palermo, Catania and Cagliari.
} 
Sectors are also distinguished in two main categories (high-tech and low-tech) by means of a dummy variable (DHT). ${ }^{15}$ The main aim of such a distinction is to test whether Jacobs externalities are more powerful for high-tech dynamic sectors, where cross fertilisation from outside the core industry is crucial for breakthroughs in product and process innovation, as in Henderson et al. (1995) for the USA case.

\section{Econometric results}

In the previous section we have sketched a modelling framework based either on the hypotheses discussed in the recent literature and on the findings concerning the distribution of innovative activities across Italian local districts. Our main purpose is to assess the extent to which the innovative output of a local industry is affected by the degree of production specialisation (PS) in the same local industry (Marshall externalities) and by the degree of industrial diversity (PD) in the district (Jacobs externalities). Moreover, we analyse the impact of complementary industries which share the same science base both in terms of specialisation (SBS) and in terms of diversity (SBD). We also control for the amount of technological opportunities (TO) which characterises each industry. ${ }^{16}$ The basic function estimated is, therefore, as follows:

$$
\mathrm{y}_{\mathrm{ij}}=\alpha+\beta \mathrm{PS}_{\mathrm{ij}}+\phi \mathrm{SBS}_{\mathrm{ij}}+\chi \mathrm{PD}_{\mathrm{j}}+\gamma \mathrm{SBD}_{\mathrm{ij}}+\delta \mathrm{TO}_{\mathrm{i}}+\varepsilon_{\mathrm{ij}}
$$

The estimation is based on 9265 observations obtained by combining 85 sectors at the threedigit level (see table A.1 in the appendix) and 109 local districts (see table A.2 in the appendix). We have excluded those sectors with no sign of innovative activity and those local labour systems with almost negligible innovative activity, that is those which have patented less than three times per year in the five years from 1990 to 1994 . Patent data for the estimation refer to annual averages for the period 1990-91, whilst employment data are from 1991 Census.

The OLS estimates of the basic function -with White robust standard errors to take into account for heteroskedasticity- are reported in the first column of table 7. The positive and statistically significant coefficient of industry specialisation $(\beta)$, the basic Marshall externalities measure, suggests that innovative activity in a certain industry is higher when it is located in an area specialised in that industry. On the one hand, this result is in contrast to Audretsch and Feldman (1999) and Kelly and Hageman (1999) who, with different methodologies and data sets, reach the

\footnotetext{
${ }^{15}$ We define high tech sectors those ones with a quota of innovative firms above the threshold of $40 \%$ according to the Italian national survey on technological activity (ISTAT, 1998).

${ }^{16}$ We have also examined the effects of two more explanatory variables but they do not prove significant in any specification of the model. The first variable is the size of local firms relative to the national average; a value greater than one can be interpreted either as a sign of market power (competition effect) or as a sign of the exploitation of increasing returns (economies of scale effect). The second variable is a propensity to innovate index based on the quota of firms which have innovated in each sector.
} 
same conclusion: innovation activities do not follow the same geographical distribution of production in the United States. On the other hand, this outcome confirms Paci and Usai (1999), who found a correlation between specialisation in production and innovation among the European regions. The Italian situation proves, unsurprisingly, closer to the European rather than to the American case. One possible explanation for this contrast is to be found in the substantial differences in the industrial structure between the two countries. In particular, Italy is characterised by a large presence of small and medium enterprises in the traditional sectors, where innovation is more incremental in nature and it is mainly performed within the operative plants. This may explain why innovation and production are mainly located in the same place. On the contrary in the USA, there is a great number of multinationals and big firms, whose innovative activity is more related to $R \& D$ laboratories, which have not got to be necessarily located near the headquarters or the production sites.

Another important result, which confirms the importance of Marshall externalities, is the positive and significant coefficient for the indicator which measures the science base cluster specialisation $(\phi)$. This result may be interpreted as evidence of localisation spillovers which are not exactly intra-sector as above, but intra-cluster of sectors with the same science base. In other words, the lower is the technological distance across industries, the easier, and probably more fruitful, may be the flow of knowledge among them [Griliches (1992)]. Moreover, if the two coefficients for specialisation are compared, one finds that Marshall externalities within the sector are not significantly different from those ones within the science base cluster, $\beta$ and $\phi$ are, as a matter of fact, 0.20 and 0.16 respectively.

As far as the role of diversity is concerned, this appears to affect innovative activity with a positive and significant impact when measured at the local district level (PD). In other words, when the diversification across industries in the local district is higher, Jacobs externalities are at work and innovative capacity is, consequently, encouraged. Such a result is confirmed when the index for the productive activities is substituted for the same indicator referred to innovative activities [see ID, innovation diversity, in specification (2)], a further confirmation of the correspondence between innovative and productive patterns.

Jacobs externalities operate at the science base cluster level, too. As a matter of fact, diversity accounts for a positive effect on innovation spatial clustering also when referred to the relative science base group (SBD). Moreover, it is worth noting that the impact of diversity referred to the whole local district (1.55) is almost twice as bigger than that of diversity at the science base cluster level (0.79) and that they are significantly different from each other. 


\subsection{Some robustness exercises}

Given that the framework for the estimation is not derived directly from a theoretically sound model, it is necessary to perform several tests to assess the robustness of the findings described above.

First of all, results prove robust with respect to the exclusion of the 1703 observations which display a zero value for the dependent variable (that is, when there are no patents for sector $i$ in district $j$ ). In the specification (3) main results are, as a matter of fact, unchanged.

Secondly, we have verified if the results depend on the threshold point for the dependent variable (i.e. an annual average of three patents in the period 1991-94) used to identify our sample of 109 local labour systems. We have estimated other two regressions (see columns 4-5) for different samples identified with a cut-off point fixed at five and ten patents per year respectively. Results were not significantly different.

Thirdly, we have estimated the basic function with the Tobit methodology, which is necessary whenever data are censored. As for this aspect, a brief digression is needed. The Tobit model proves a more efficient estimation method with respect to OLS if one accepts that the phenomenon under exam -innovative activity- can be negative and, in that case, not observable. From a technical point of view this implies that there exists a latent variable which is not observed if negative: the dependent variable is therefore censored since negative observations are omitted and substituted with zero. From a more pragmatic perspective this means that technological regress in a specific local industry is possible. This may happen whenever, given a certain stock of technological knowledge, the amount of innovation activity in certain period does not exceed the natural decay of such a stock. If this perspective is found realistic, Tobit analysis provides more efficient results than OLS. Tobit estimates for the basic function above, reported in column 6 , show, nevertheless, that the main results are maintained.

A final test of robustness is represented by an extension of the basic model to take into account for differences which may arise due to the dimension of the districts (dummy for metropolis, DM) and to the sectoral characteristics (dummy for high tech industries, DHT). Such dummies are inserted both as additive ones for changes in the intercept and as multipliers of the diversity coefficient in order to test whether there is any significant difference in the impact of Jacobs externalities with respect to the dimension of cities and the type of sector involved. More specifically, the former dummy allows to test whether, as argued by Glaeser et al. (1992), Jacobs externalities are more likely to operate within metropolitan areas; whilst the latter dummy tests if such externalities are more powerful for high-tech sectors, as in Henderson et al. (1995) for the USA case. The encompassing model which includes both metropolitan and high-tech dummies is as follows: 


$$
\mathrm{y}_{\mathrm{ij}}=\alpha+\beta \mathrm{PS}_{\mathrm{ij}}+\phi \mathrm{SBS}_{\mathrm{ij}}+\chi \mathrm{PD}_{\mathrm{j}}+\gamma \mathrm{SBD}_{\mathrm{j}}+\delta \mathrm{TO}_{\mathrm{i}}+\alpha_{1} \mathrm{DM}+\chi_{1} \mathrm{PD}_{\mathrm{j}} * \mathrm{DM}+\alpha_{2} \mathrm{DHT}+\chi_{2} \mathrm{PD}_{\mathrm{j}} * \mathrm{DHT}+\varepsilon_{\mathrm{ij}}
$$

The results of the OLS estimation of this function are reported in column (1) of Table 8 . First, one notices that all the new dummies are significant while the other four explanatory variables previously discussed (PS, SBS, SBD and TO) maintain their significance and sign. This confirms their robustness to different specifications and the main conclusions already put forward. However, some interesting changes appear with respect to the interactive dummies. The coefficients for the multiplicative dummies are all positive and statistically significant signalling the importance of differentiating Jacobs externalities according to the characteristics of the local districts and of the industrial sectors. This differentiation can be summarised in the table below where the impact of diversity (the coefficient of PD) is reported with respect to four cases:

\begin{tabular}{|l|c|c|}
\hline & High tech sectors (DHT=1) & Low tech sectors (DHT=0) \\
\hline Metropolitan districts $(\mathrm{DM}=1)$ & $\chi+\chi_{1}+\chi_{2}$ & $\chi+\chi_{1}$ \\
& $(20.72)$ & $(14.16)$ \\
\hline No metropolitan districts $(\mathrm{DM}=0)$ & $\chi+\chi_{2}$ & $\chi$ \\
& $(5.07)$ & $(-0.46)$ \\
\hline
\end{tabular}

Thus, the most interesting result reported in regression (1) is that not only are Jacobs externalities more robust when one combines high tech sectors in metropolitan districts (the impact being $\chi+\chi_{1}+\chi_{2}=20.72$ ), but also that they do not exist for low tech sectors located in small districts (the impact being in that case just $\chi$ which is negative and significant and equal to -0.46). Interestingly, these results are in line with the findings of Glaeser et al. (1992) and Henderson et al. (1995) for large towns and high tech sectors in the USA, respectively.

As further tests of robustness, in columns (2) and (3) we present the results of the estimations of the two sets of dummies: all variables maintain the same sign and significance but for the coefficient of PD. In column (4), the Tobit model is also applied. Main results are consistent with OLS estimates but, again, for the coefficient of PD $(\chi)$ which remains positive even though not significant. This means that the conclusion that variety has a negative impact on innovation activity in low tech sectors located in small districts is not robust and should be taken with caution.

Finally, we control for the robustness of our results also with respect to the inclusion of fixed effects across sectors and across local districts. However, we did not get any improvement in the estimation due to the fact that sectoral differences are already considered thanks to the opportunity index; while as regards the local district dummies, they do not prove significant but for the greater cities which are already taken into account by the metropolitan dummy. 


\section{Conclusions}

The aim of this paper is to investigate on the controversial effects of industrial diversity and specialisation on the spatial agglomeration of the innovative activities. The more recent literature has distinguished between two contrasting types of externalities: Marshall (specialisation) or Jacobs (diversity) economies. Thanks to a rich and detailed database on innovation and production at the local and sectoral level, we are able to separately account for the two effects. Further, we investigate on the role of complementary science base industries both in term of specialisation and diversity. Finally, we test whether there is any significant difference in the impact of diversity with respect to the dimension of cities and the type of sector involved.

According to the estimation results there are clear signs that the spatial distribution of innovative activities among the Italian local districts is affected by both Marshall externalities (localisation economies), associated to industrial specialisation within the same sector and within the same science base cluster, and Jacobs externalities (urbanisation economies), associated to the degree of diversity of the local districts and of the science base cluster. This is an important result which contrasts with some recent literature on the case of the United States where the two types of externalities have been considered as contrasting and the specialisation economies were not found. On the contrary, in our work these two externalities are not necessarily opposed and, once properly defined, they can prove to work together.

Further, with respect to the urbanisation economies, it is worth noting that they play a different role depending on the nature of the local district (whether it is a metropolitan area or not) and on the type of industry (high vs low tech sectors). More specifically, Jacobs externalities are more powerful in high tech sectors and in metropolitan areas, whilst their role is contradictory in low tech sectors in small districts.

This paper is still a work in progress and several future extensions appear potentially very fruitful. In particular it may prove very interesting to deepen the analysis of spatial diffusion of technology by looking at spillovers across local districts rather than just within them, as in this work. This implies a more technical analysis based on spatial econometrics methodologies. Moreover, it may prove very interesting to analyse the different paths followed by the local labour systems under exam in order to understand the dynamic properties of technological creation and diffusion. 


\section{References}

Arthur W.B. (1988) Self-reinforcing Mechanisms in Economics, in P. Anderson, K. Arrow and D. Pines (eds.) The Economy as an Evolving Complex System. Redwood City: Addison-Wasley Publishing Company.

Audretsch D. and Feldman M. (1996) R\&D Spillovers and the Geography of Innovation and Production, American Economic Review, 86, 631-640.

Bartelsman E. Caballero R. and Lyons R. (1994) Customer- and Supplier- Driven Externalities, American Economic Review, 84, 1075-1084.

Becattini G. (1987) (ed.) Mercato e Forze Locali. Il Distretto Industriale. Bologna: Il Mulino.

Breschi S. (1997) The Geography of Innovation: a Cross-section Analysis, CESPRI WP n. 95. Milano: Università Bocconi.

Brulhart M. (1998), Economic Geography, Industry Location and Trade: The Evidence, World Economy, 21, 775-801.

Brusco S. (1982) The Emilian Model: Productive Decentralisation and Social Integration, Cambridge Journal of Economics, 6, 167-184.

Camagni R. (1991) (ed.) Innovation Networks: Spatial Perspectives. London: Belhaven Press.

Caniels M. (1999) Knowledge Spillovers and Economic Growth: Regional Growth Differentials across Europe. Cheltenham: Edward Elgar.

Capello R. (1999) Spatial Transfer of Knowledge in High Technology Milieux: Learning versus Collective Learning Processes, Regional Studies, 33, 353-365.

Coe D. and Helpman E. (1995) International R\&D Spillovers, European Economic Review, 39, 859-87.

Cooke P. and Morgan K. (1994) The Creative Milieu: a Regional Perspective on Innovation, in M. Dodgson and R. Rothwell (eds.) The Handbook of Industrial Innovation. Cheltenham: Edward Elgar.

Ellison G. and Glaeser E. (1999) The Geographic Concentration of Industry: Does Natural Advantage Explain Agglomeration?, American Economic Review Papers and Proceedings, 89, 301-316.

Evenson R. (1993) Patents, R\&D and Invention Potential: International Evidence, American Economic Review Papers and Proceedings, 83, 463-468.

Feldman M. and Audretsch D. (1999) Innovation in Cities: Science-Based Diversity, Specialization and Localized Competition, European Economic Review, 43, 409-429.

Feldman M. (1994) The Geography of Innovation. Kluwer Academic Publisher.

Forni M. and Paba S. (1999) Knowledge Spillovers and the Growth of Local Industries, University of Modena, mimeo.

Glaeser E., Kallal H., Scheinkman J. and Sheifler A. (1992) Growth of Cities, Journal of Political Economy, 100, 1126-52.

Griliches Z. (1990) Patent Statistics as Economic Indicators: A Survey, Journal of Economic Literature, 28, 1661-1707.

Griliches Z. (1992) The Search for R\&D Spillovers, Scandinavian Journal of Economics, 94, 2947. 
Henderson V, Kuncoro A. and Turner M. (1995) Industrial Development of Cities, Journal of Political Economy, 103, 1067-1090.

ISTAT (1998), Statistiche sulla ricerca scientifica e l'innovazione tecnologica, Roma.

Jacobs J. (1969) The Economy of Cities. London: Jonathan Cape.

Jaffe A., Trajtenberg M. and Henderson R. (1993) Geographic Localisation of Knowledge Spillovers as Evidenced by Patent Citations, Quarterly Journal of Economics, 108, 577-598.

Kelly M. and Hageman A. (1999) Marshallian Externalities in Innovation, Journal of Economic Growth, 4, 39-54.

Krugman P. (1991) Economic Geography and Trade. Cambridge, MA: MIT Press.

Lamorgese A. (1997) Externalities, Economic Geography and Growth: a Cross-section Analysis, CESPRI WP n. 100.

Lawson C. and Lorenz E. (1999) Collective Learning, Tacit Knowledge and Regional Innovative Capacity, Regional Studies, 33, 305-317.

Lucas R.E. (1993), Making a Miracle, Econometrica, 61, 251-272.

Marshall A. (1890) Principles of Economics. London: Macmillan.

Ottaviano I. and Puga D. (1998), Agglomeration in the Global Economy: A Survey of the "New Economic Geography", World Economy, 21, 707-731.

Paci R. and Usai S. (1999) Technological enclaves and industrial districts. An analysis of the regional distribution of innovative activity in Europe, Regional Studies, forthcoming.

Pavitt K. (1982) R\&D, Patenting and Innovative Activities. A Statistical Exploration, Research Policy, 11, 33-51.

Pyke F., Becattini G. and Sengenberger W. (1990) (eds.) Industrial Districts and Inter-firm Cooperation in Italy. Geneva: International Institute for Labour Studies.

Regional Studies (1999) Special Issue on: Regional Networking, Collective Learning and Innovation in High Technology SMEs in Europe, 33, n.4.

Romer P. (1986) Increasing Returns and Long-run Growth, Journal of Political Economy, 94, 10021037.

Sforzi F. (1997) (ed.) I sistemi locali del lavoro 1991, Argomenti n.10. Roma: ISTAT.

Verspagen B. (1999) European Regional Clubs: Do they Exist and where are they Heading? On Economic and Technological Differences between European Regions, in J. Adams and F. Pigliaru (eds), Economic Growth and Change. Cheltenham: Edward Elgar.

Von Hippel E. (1995) Sticky Information and the Locus of Problem Solving: Implications for Innovation, Management Science, 40, 429-439.

Weber A. (1909) Theory of Locations of Industries. Chicago: University Press. 
Table 1. Innovative activity in the macro-regions (annual average)

\begin{tabular}{|c|c|c|c|c|c|c|}
\hline & \multicolumn{3}{|c|}{ Total patents } & \multirow[b]{2}{*}{$\%$} & \multicolumn{2}{|c|}{ Patents per 100,000 inhabitants } \\
\hline & $1981-85$ & $\%$ & 1990-94 & & $1981-85$ & 1990-94 \\
\hline North-West & 2594 & 58.0 & 6069 & 54.3 & 17.0 & 40.6 \\
\hline North-East & 1106 & 24.7 & 3056 & 27.4 & 10.6 & 29.5 \\
\hline Centre & 627 & 14.0 & 1588 & 14.2 & 5.8 & 14.6 \\
\hline South & 148 & 3.3 & 460 & 4.1 & 0.7 & 2.2 \\
\hline ITALY & 4474 & 100.0 & 11173 & 100.0 & 7.9 & 19.7 \\
\hline
\end{tabular}

Source: CRENoS patent databank 
Table 2. Ranking of 25 most innovative districts. Total patents

\begin{tabular}{|c|c|c|c|c|c|c|}
\hline \multirow[t]{2}{*}{ Local district } & \multirow{2}{*}{$\begin{array}{l}\text { N. patents } \\
\text { 1981-94 }\end{array}$} & \multirow{2}{*}{$\begin{array}{c}\% \text { of Italian } \\
\text { total } \\
1981-94\end{array}$} & \multicolumn{3}{|c|}{ Ranking by total patents } & \multirow{2}{*}{$\begin{array}{l}\text { Ranking by } \\
\text { patent p.c. } \\
1981-94\end{array}$} \\
\hline & & & $1981-94$ & $1981-85$ & 1990-94 & \\
\hline MILANO & 4804 & 21.3 & 1 & 1 & 1 & 4 \\
\hline TORINO & 1780 & 7.9 & 2 & 2 & 2 & 11 \\
\hline ROMA & 1258 & 5.6 & 3 & 3 & 3 & 115 \\
\hline BOLOGNA & 1078 & 4.8 & 4 & 4 & 4 & 6 \\
\hline FIRENZE & 518 & 2.3 & 5 & 6 & 5 & 63 \\
\hline PORDENONE & 444 & 2.0 & 6 & 7 & 7 & 1 \\
\hline PADOVA & 338 & 1.5 & 7 & 13 & 6 & 54 \\
\hline BERGAMO & 338 & 1.5 & 8 & 15 & 8 & 45 \\
\hline COMO & 301 & 1.3 & 9 & 8 & 14 & 41 \\
\hline NOVARA & 298 & 1.3 & 10 & 9 & 16 & 3 \\
\hline BUSTO ARSIZIO & 293 & 1.3 & 11 & 17 & 10 & 31 \\
\hline LECCO & 292 & 1.3 & 12 & 16 & 9 & 16 \\
\hline BRESCIA & 291 & 1.3 & 13 & 14 & 11 & 38 \\
\hline GENOVA & 280 & 1.2 & 14 & 10 & 12 & 123 \\
\hline DESIO & 258 & 1.1 & 15 & 11 & 15 & 75 \\
\hline UDINE & 251 & 1.1 & 16 & 18 & 13 & 50 \\
\hline VARESE & 246 & 1.1 & 17 & 12 & 18 & 19 \\
\hline IVREA & 228 & 1.0 & 18 & 5 & 34 & 7 \\
\hline PARMA & 226 & 1.0 & 19 & 21 & 23 & 26 \\
\hline PAVIA & 202 & 0.9 & 20 & 19 & 25 & 15 \\
\hline MONTEBELLUNA & 188 & 0.8 & 21 & 20 & 27 & 2 \\
\hline VIGEVANO & 186 & 0.8 & 22 & 31 & 20 & 29 \\
\hline FERRARA & 185 & 0.8 & 23 & 22 & 21 & 23 \\
\hline SESTO CALENDE & 185 & 0.8 & 24 & 34 & 17 & 5 \\
\hline SAVONA & 183 & 0.8 & 25 & 33 & 19 & 8 \\
\hline
\end{tabular}

Source: CRENoS patent databank 
Table 3. Ranking of 25 most innovative districts. Patents per 100,000 inhabitants

\begin{tabular}{|c|c|c|c|c|c|}
\hline \multirow[t]{2}{*}{ Local district } & Patents p.c. & \multicolumn{3}{|c|}{ Ranking by patents p.c. } & \multirow{2}{*}{$\begin{array}{r}\text { Ranking by } \\
\text { total patent } \\
1981-9\end{array}$} \\
\hline & 1981-94 & 1981-94 & $1981-85$ & 1990-94 & \\
\hline PORDENONE & 200 & 1 & 4 & 2 & 6 \\
\hline MONTEBELLUNA & 187 & 2 & 3 & 3 & 21 \\
\hline NOVARA & 175 & 3 & 6 & 8 & 10 \\
\hline MILANO & 166 & 4 & 8 & 7 & 1 \\
\hline SESTO CALENDE & 158 & 5 & 18 & 1 & 24 \\
\hline BOLOGNA & 158 & 6 & 9 & 5 & 4 \\
\hline IVREA & 152 & 7 & 1 & 31 & 18 \\
\hline SAVONA & 138 & 8 & 22 & 4 & 25 \\
\hline FABRIANO & 136 & 9 & 121 & 6 & 66 \\
\hline CHIERI & 131 & 10 & 14 & 11 & 34 \\
\hline TORINO & 115 & 11 & 10 & 23 & 2 \\
\hline AVIGLIANA & 106 & 12 & 65 & 10 & 48 \\
\hline IMOLA & 105 & 13 & 19 & 14 & 36 \\
\hline MORTARA & 104 & 14 & 119 & 12 & 84 \\
\hline PAVIA & 103 & 15 & 12 & 22 & 20 \\
\hline LECCO & 102 & 16 & 23 & 16 & 12 \\
\hline ARZIGNANO & 101 & 17 & 13 & 49 & 51 \\
\hline BORGOMANERO & 98 & 18 & 84 & 15 & 43 \\
\hline VARESE & 97 & 19 & 17 & 29 & 17 \\
\hline ORTISEI & 96 & 20 & 2 & 45 & 190 \\
\hline MIRANDOLA & 95 & 21 & 24 & 21 & 54 \\
\hline VIGNOLA & 95 & 22 & 162 & 9 & 57 \\
\hline FERRARA & 94 & 23 & 20 & 18 & 23 \\
\hline FAENZA & 88 & 24 & 34 & 24 & 55 \\
\hline CORREGGIO & 88 & 25 & 76 & 20 & 112 \\
\hline
\end{tabular}

Source: CRENoS patent databank 
Table 4. Ranking of most innovative sectors. Total patents

\begin{tabular}{|c|c|c|c|c|c|}
\hline \multirow[t]{2}{*}{ Sector } & \multirow{2}{*}{$\begin{array}{r}\text { N. patents } \\
1981-94\end{array}$} & \multirow{2}{*}{$\begin{array}{r}\% \text { of Italian total } \\
1981-94\end{array}$} & \multicolumn{2}{|c|}{ Ranking by total patents } & \multirow[b]{2}{*}{$1990-94$} \\
\hline & & & $1981-94$ & $1981-85$ & \\
\hline General purpose machinery & 4447 & 19.7 & 1 & 1 & 1 \\
\hline Basic chemicals & 2534 & 11.2 & 2 & 2 & 2 \\
\hline Machinery, engines and turbines & 1368 & 6.1 & 3 & 3 & 3 \\
\hline Parts and accessories for motor vehicles & 1122 & 5.0 & 4 & 4 & 5 \\
\hline Pharmaceutics & 945 & 4.2 & 5 & 13 & 4 \\
\hline Television and radio receivers & 871 & 3.9 & 6 & 5 & 6 \\
\hline Electrical equipment & 829 & 3.7 & 7 & 6 & 8 \\
\hline Electronic components & 824 & 3.7 & 8 & 14 & 7 \\
\hline Optical instruments & 767 & 3.4 & 9 & 7 & 10 \\
\hline Plastic products & 754 & 3.3 & 10 & 10 & 9 \\
\hline Instruments for measuring & 685 & 3.0 & 11 & 8 & 11 \\
\hline Chemical products & 594 & 2.6 & 12 & 11 & 12 \\
\hline Other manufacturing & 584 & 2.6 & 13 & 12 & 13 \\
\hline Office machinery and computing & 538 & 2.4 & 14 & 9 & 14 \\
\hline Machine-tools & 434 & 1.9 & 15 & 15 & 16 \\
\hline Cutlery and general hardware & 433 & 1.9 & 16 & 16 & 15 \\
\hline Television and radio transmitters & 276 & 1.2 & 17 & 17 & 17 \\
\hline Furniture & 262 & 1.2 & 18 & 20 & 18 \\
\hline Fabricated metal products & 244 & 1.1 & 19 & 18 & 20 \\
\hline Structural metal products & 243 & 1.1 & 20 & 19 & 19 \\
\hline
\end{tabular}

Source: CRENoS patent databank 
Table 5. Specialization and diversity in production activities among the 25 most innovative districts.

1 MILANO

Pharmaceutics (0.62)

2 TORINO

3 ROMA

4 BOLOGNA

5 FIRENZE

6 PORDENONE

7 PADOVA

8 BERGAMO

9 COMO

10 NOVARA

11 BUSTO ARSIZIO

12 LECCO

13 BRESCIA

14 GENOVA

15 DESIO

16 UDINE

17 VARESE

18 IVREA

19 PARMA

20 PAVIA

21 MONTEBELLUNA

22 VIGEVANO

23 FERRARA

24 SESTO CALENDE

25 SAVONA
Motor vehicles (0.79)

Pharmaceutics (0.62)
Motor vehicles (0.79)

Television and radio transmitters $(0.68)$

Agro-chemical products (0.69)

Luggage and handbags (0.82)

Television and radio receivers $(0.82)$

Steam generators $(0.71)$

Transport equipment $(0.86)$

Finishing of textiles (10.82)

Refined petroleum products $(0.73)$

Finishing of textiles (0.68)

Fabricated metal products $(0.66)$

Casting of metals (0.65)

Building and repairing of ships (0.88)

Furniture (0.72)

Sawmilling and planing of wood (0.87)

Aircraft and spacecraft (0.74)

Office machinery and computing (0.96)

Steam generators $(0.80)$

Watches and clocks (0.88)

Footwear (0.89)

Accumulators and primary cells (0.86)

Basic chemicals (0.86)

Watches and clocks (0.90)

Ceramic products $(0.88)$
Television and radio receivers (0.59) 0.63

Accessories for motor vehicles (0.62) $\quad 0.74$

Publishing (0.65) $\quad 0.72$

Railway (0.61) $\quad 0.67$

Optical instruments (0.62) $\quad 0.67$

Domestic appliances (0.81) $\quad 0.77$

Footwear (0.63) $\quad 0.68$

Cement, lime and plaster (0.75) $\quad 0.68$

Treatment of fish $(0.80) \quad 0.76$

Electronic components (0.60) $\quad 0.74$

Steam generators $(0.67) \quad 0.75$

Lighting equipment $(0.56) \quad 0.71$

Basic precious and non-ferrous metals (0.62) $\quad 0.71$

Basic iron and steel (0.75) $\quad 0.73$

Wood panel (0.68) $\quad 0.74$

Watches and clocks (0.87) $\quad 0.73$

Electricity distribution and control apparatus (0.70) $\quad 0.69$

Motor vehicles (0.76) $\quad 0.85$

Glass products $(0.79) \quad 0.74$

Dairy-farming products $(0.79) \quad 0.67$

Sports goods (0.81) $\quad 0.85$

Television and radio receivers (0.78) $\quad 0.70$

Grain mill and starch products $(0.70) \quad 0.79$

Domestic appliances $(0.88) \quad 0.77$

Building and repairing of ships (0.80) $\quad 0.78$

(1) Standardised Productive Specialization (SPS) indeces are computed according to the formula: $(P S-1) /(P S+1)$

and are, therefore, constrained within the interval $(-1,1)$.

${ }^{(2)}$ Gini concentration coefficient defined within the interval $(0,1)$.

Source: CRENoS patent databank and Istat 
Table 6. Specialization and diversity in innovation activities among the 25 most innovative districts

Rank. Local district

Highest specialization index ${ }^{(1)}$

Second highest specialization index ${ }^{(1)}$ Concentration index ${ }^{(2)}$

\begin{aligned} 1 & MILANO \\ 2 & TORINO \\ 3 & ROMA \\ 4 & BOLOGNA \\ 5 & FIRENZE \\ 6 & PORDENONE \\ 7 & PADOVA \\ 8 & BERGAMO \\ 9 & COMO \\ 10 & NOVARA \\ 11 & BUSTO ARSIZIO \\ 12 & LECCO \\ 13 & BRESCIA \\ 14 & GENOVA \\ 15 & DESIO \\ 16 & UDINE \\ 17 & VARESE \\ 18 & IVREA \\ 19 & PARMA \\ 20 & PAVIA \\ 21 & MONTEBELLUNA \\ 22 & VIGEVANO \\ 23 & FERRARA \\ 24 & SESTO CALENDE \\ 25 & SAVONA \\ & \\ \hline & \\ 13 & \end{aligned}

Publishing (0.53)

Prepared animal feeds $(0.72)$

Grain mill and starch products (0.68)

Luggage and handbags (0.75)

Knitwear articles $(0.88)$

Special purpose machinery $(0.77)$

Builders' carpentry and joinery (0.59)

Electricity distribution and control apparatus (0.56)

Printing (0.67)

Basic precious and non-ferrous metals $(0.90)$

Preparation and spinning of textile fibres (0.62)

Building and repairing of ships (0.78)

Knitwear articles $(0.89)$

Accumulators and primary cells $(0.82)$

Watches and clocks $(0.81)$

Cement, lime and plaster (0.89)

Agro-chemical products $(0.65)$

Games and toys (0.87)

Treatment of fruit and vegetables (0.93)

Pharmaceutics $(0.56)$

Footwear (0.96)

Wood panel (0.77)

Varnishes $(0.80)$

Special purpose machinery $(0.77)$

Printing (0.90)
Refined petroleum products $(0.40)$

0.80

Motor vehicles (0.55)

0.81

Aircraft and spacecraft (0.64)

0.78

Tobacco products $(0.71)$

0.80

Wearing apparel (0.72)

0.79

Domestic appliances (0.74)

0.87

Transport equipment $(0.56)$

0.79

Finishing of textiles (0.56) $\quad 0.78$

Structural non-refractory clay (0.58) $\quad 0.81$

Processing of metal (0.85) $\quad 0.90$

Building and repairing of ships (0.54) 0.83

Preparation and spinning of textile fibres $(0.68)$

0.81

0.81

0.78

0.78

0.86

Ceramic products $(0.86)$

0.78

Office machinery and computing (0.80) 0.90

Grain mill and starch products (0.92) $\quad 0.82$

Agro-chemical products (0.56) $\quad 0.86$

Tanning and dressing of leather (0.90) 0.91

Non-metallic mineral products $(0.66) \quad 0.83$

Chemical products $(0.66) \quad 0.91$

Instruments for measuring (0.61) $\quad 0.87$

Chemical products $(0.84) \quad 0.92$

\footnotetext{
(1) Standardised Innovation Specialization (SIS) indeces are computed according to the formula: $(I S-1) /(I S+1)$

and are, therefore, constrained within the interval $(-1,1)$.

(2) Gini concentration coefficient defined within the interval $(0,1)$.
} 
Table 7. Determinants of the localisation of innovative activities

Dependent variable: patent per 100.000 inhabitants

White-robust standard errors in parentheses

\begin{tabular}{|c|c|c|c|c|c|c|c|}
\hline & \multirow[b]{2}{*}{ Explanatory variables } & \multicolumn{5}{|c|}{ OLS } & \multirow[t]{2}{*}{ TOBIT } \\
\hline & & (1) & (2) & (3) & (4) & (5) & \\
\hline & \multirow[t]{2}{*}{ Constant } & -0.46 & -0.56 & -0.57 & -0.49 & -0.96 & -1.26 \\
\hline & & $(0.11)^{* *}$ & $(0.09) * *$ & $(-0.14) * *$ & $(0.15) * *$ & $(0.32)^{* *}$ & $(0.08) * *$ \\
\hline \multirow[t]{2}{*}{ PS } & Production specialisation & 0.20 & 0.20 & 0.25 & 0.26 & 0.35 & 0.24 \\
\hline & & $(0.03) * *$ & $(0.03) * *$ & $(0.03) * *$ & $(0.039) * *$ & $(0.07)^{* *}$ & $(0.04) * *$ \\
\hline \multirow[t]{2}{*}{ SBS } & Science base specialisation & 0.16 & 0.20 & 0.24 & 0.19 & 0.30 & 1.14 \\
\hline & & $(0.04)^{* *}$ & $(0.05) * *$ & $(0.06) * *$ & $(0.07)^{* *}$ & $(0.14) *$ & $(0.07)^{*}$ \\
\hline \multirow[t]{2}{*}{ PD } & Production diversity & 1.55 & & 1.71 & 1.53 & 3.07 & 3.22 \\
\hline & & $(0.40) * *$ & & $(0.50) * *$ & $(0.56)^{* *}$ & $(1.16)^{* *}$ & $(0.37) * *$ \\
\hline \multirow[t]{2}{*}{ SBD } & Science base diversity & 0.79 & 0.83 & 1.12 & 0.84 & 1.00 & 1.25 \\
\hline & & $(0.19)^{* *}$ & $(0.22)^{* *}$ & $(0.25)^{* *}$ & $(0.25)^{* *}$ & $(0.40)^{*}$ & $(0.27) * *$ \\
\hline \multirow[t]{2}{*}{ TO } & Technological opportunity & 0.01 & 0.01 & 0.01 & 0.02 & 0.02 & 0.02 \\
\hline & & $(0.00) * *$ & $(0.00)^{* *}$ & $(0.00)^{* *}$ & $(0.00)^{* *}$ & $(0.00)^{* *}$ & $(0.00) * *$ \\
\hline \multirow[t]{7}{*}{ ID } & Innovation diversity & & 3.40 & & & & \\
\hline & & & $(0.37) * *$ & & & & \\
\hline & Sigma & & & & & & 1.65 \\
\hline & & & & & & & $(0.01)^{* *}$ \\
\hline & No. Obs. & 9265 & 9265 & 7503 & 6460 & 3570 & 9265 \\
\hline & Adj. R-squared & 0.21 & 0.21 & 0.21 & 0.25 & 0.26 & \\
\hline & Log-likelihood & & & & & & -15465.60 \\
\hline
\end{tabular}


Dependent variable: patent per 100.000 inhabitants

White-robust standard errors in parentheses

\begin{tabular}{|c|c|c|c|c|c|}
\hline & \multirow[b]{2}{*}{ Explanatory variables } & \multicolumn{3}{|c|}{ OLS } & \multirow[t]{2}{*}{ TOBIT } \\
\hline & & (1) & (2) & (3) & \\
\hline & Constant & 0.24 & -0.05 & -0.17 & -0.63 \\
\hline & & $(0.10)^{*}$ & $(0.04)^{*}$ & $(-0.05)^{* *}$ & $(0.09) * *$ \\
\hline \multirow[t]{2}{*}{ PS } & Production specialisation & 0.20 & 0.19 & 0.20 & 0.27 \\
\hline & & $(0.03) * *$ & $(0.03) * *$ & $(0.03) * *$ & $(0.04) * *$ \\
\hline \multirow[t]{2}{*}{ SBS } & Science base specialisation & 0.13 & 0.11 & 0.19 & 0.14 \\
\hline & & $(0.04)^{* *}$ & $(0.04) *$ & $(0.05) * *$ & $(0.07) *$ \\
\hline \multirow[t]{2}{*}{ PD } & Production diversity & -1.49 & -0.15 & 0.21 & 0.38 \\
\hline & & $(0.48) * *$ & $(0.18) *$ & $(0.22)$ & $(0.43)$ \\
\hline \multirow[t]{2}{*}{ SBD } & Science base diversity & 0.53 & 0.67 & 0.65 & 0.94 \\
\hline & & $(0.18) * *$ & $(0.18)^{*}$ & $(0.18) * *$ & $(0.26) * *$ \\
\hline \multirow[t]{2}{*}{ TO } & Technological opportunity & 0.01 & 0.01 & 0.01 & 0.01 \\
\hline & & $(0.00) * *$ & $(0.00)^{* *}$ & $(0.00) * *$ & $(0.00) * *$ \\
\hline \multirow[t]{2}{*}{$\mathrm{DM}$} & Metropolitan areas dummy & -4.37 & & -4.38 & -3.90 \\
\hline & & $(2.04) *$ & & $(2.07)^{*}$ & $(0.50) * *$ \\
\hline \multirow[t]{2}{*}{$\mathrm{PD} * \mathrm{DM}$} & Production diversity $*$ & 15.65 & & 15.67 & 14.20 \\
\hline & metropolitan areas dummy & $(6.88) *$ & & $(7.00) *$ & $(1.64) * *$ \\
\hline \multirow[t]{2}{*}{ DHT } & High-tech sectors dummy & -1.48 & -1.48 & & -0.86 \\
\hline & & $(0.35)^{* *}$ & $(0.36)^{* *}$ & & $(0.15) * *$ \\
\hline \multirow[t]{7}{*}{$\mathrm{PD} * \mathrm{DHT}$} & Production diversity $*$ & 6.56 & 6.57 & & 4.92 \\
\hline & high-tech sectors dummy & $(1.55)^{* *}$ & $(1.59)^{* *}$ & & $(0.62) * *$ \\
\hline & Sigma & & & & 1.63 \\
\hline & & & & & $(0.01)^{* *}$ \\
\hline & No. Obs. & 9265 & 9265 & 9265 & 9265 \\
\hline & Adj. R-squared & 0.24 & 0.22 & 0.22 & \\
\hline & Log-likelihood & & & & -15359.39 \\
\hline
\end{tabular}


Figure 1. Total patents (annual average 1981-85)

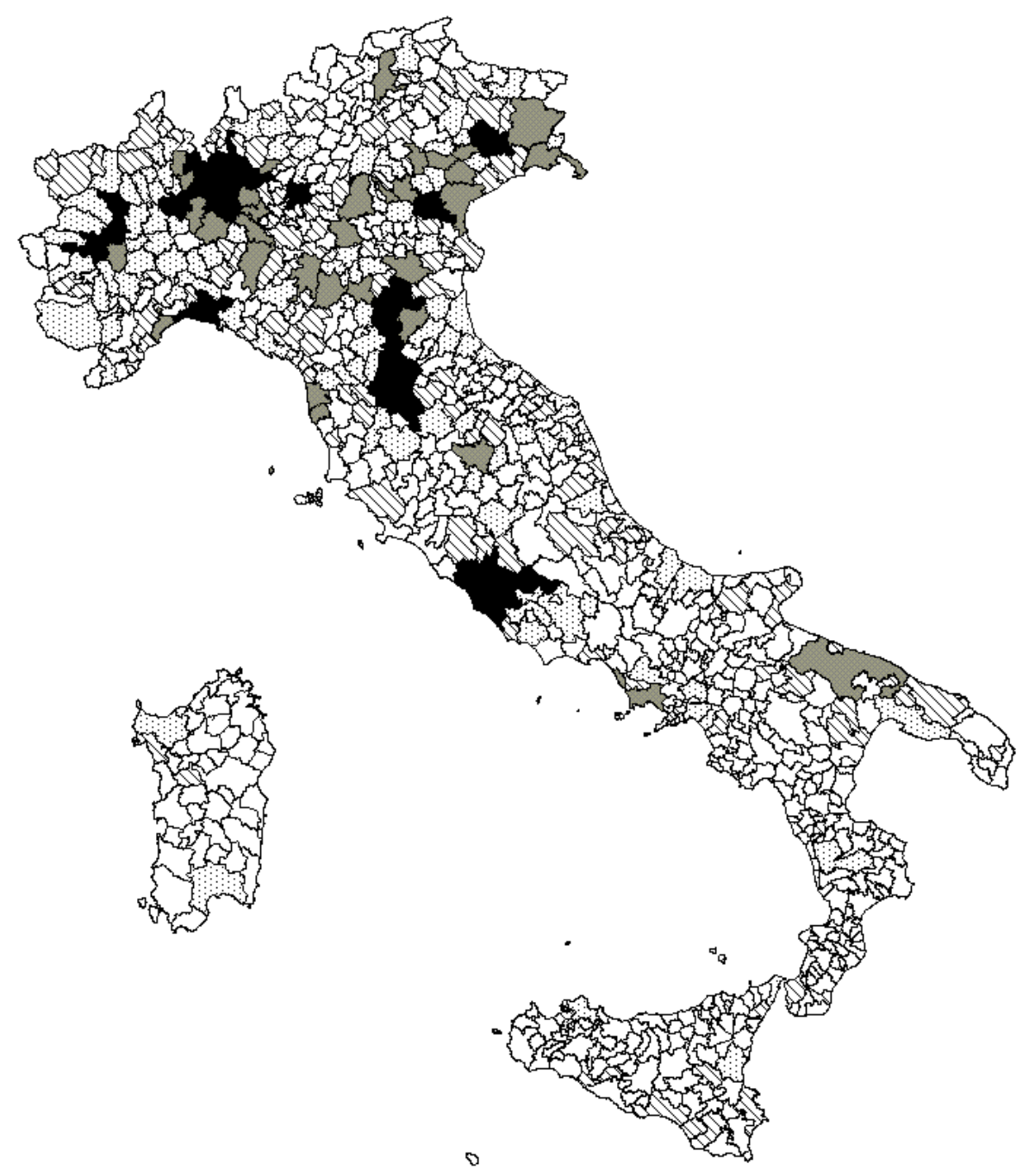

Range (frequence):

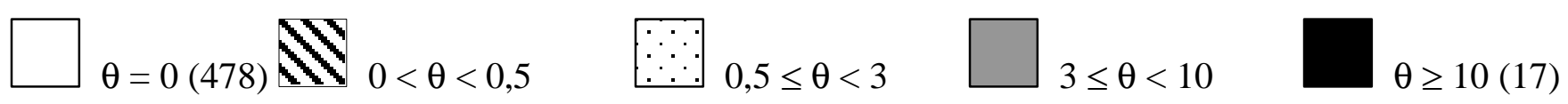

Source: CRENoS patent databank 
Figure 2. Total patents (annual average 1990-94)

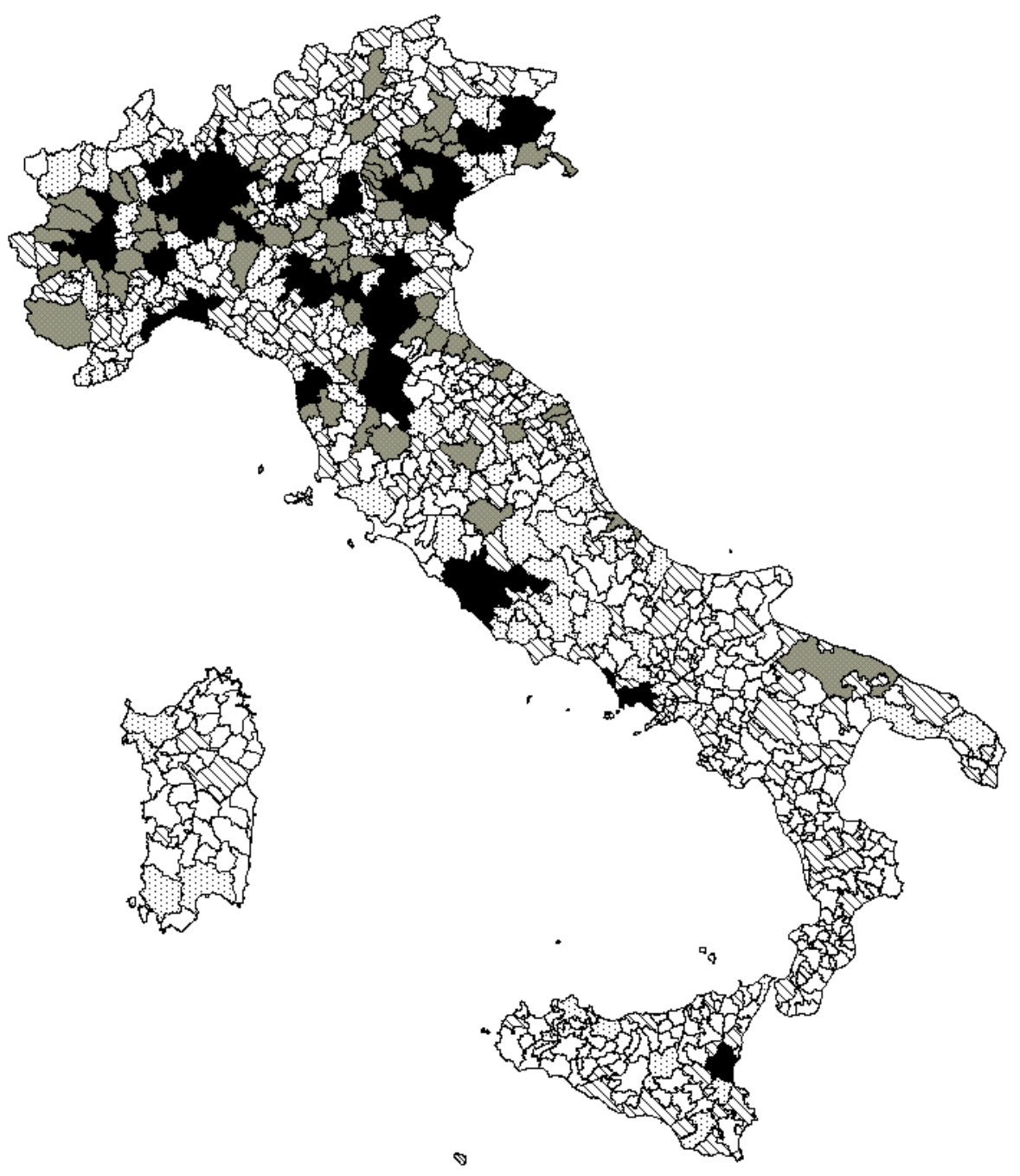

Range (frequence):

$\square_{\theta=0} \boldsymbol{W}_{0<\theta<0,5} \quad \because \theta_{0,5} \leq \theta<3(141) \square_{3 \leq \theta<10} \quad \theta \geq 10(42)$

Source: CRENoS patent databank 
Figure 3. Total patents per 100.000 inhabitants (1981-85)

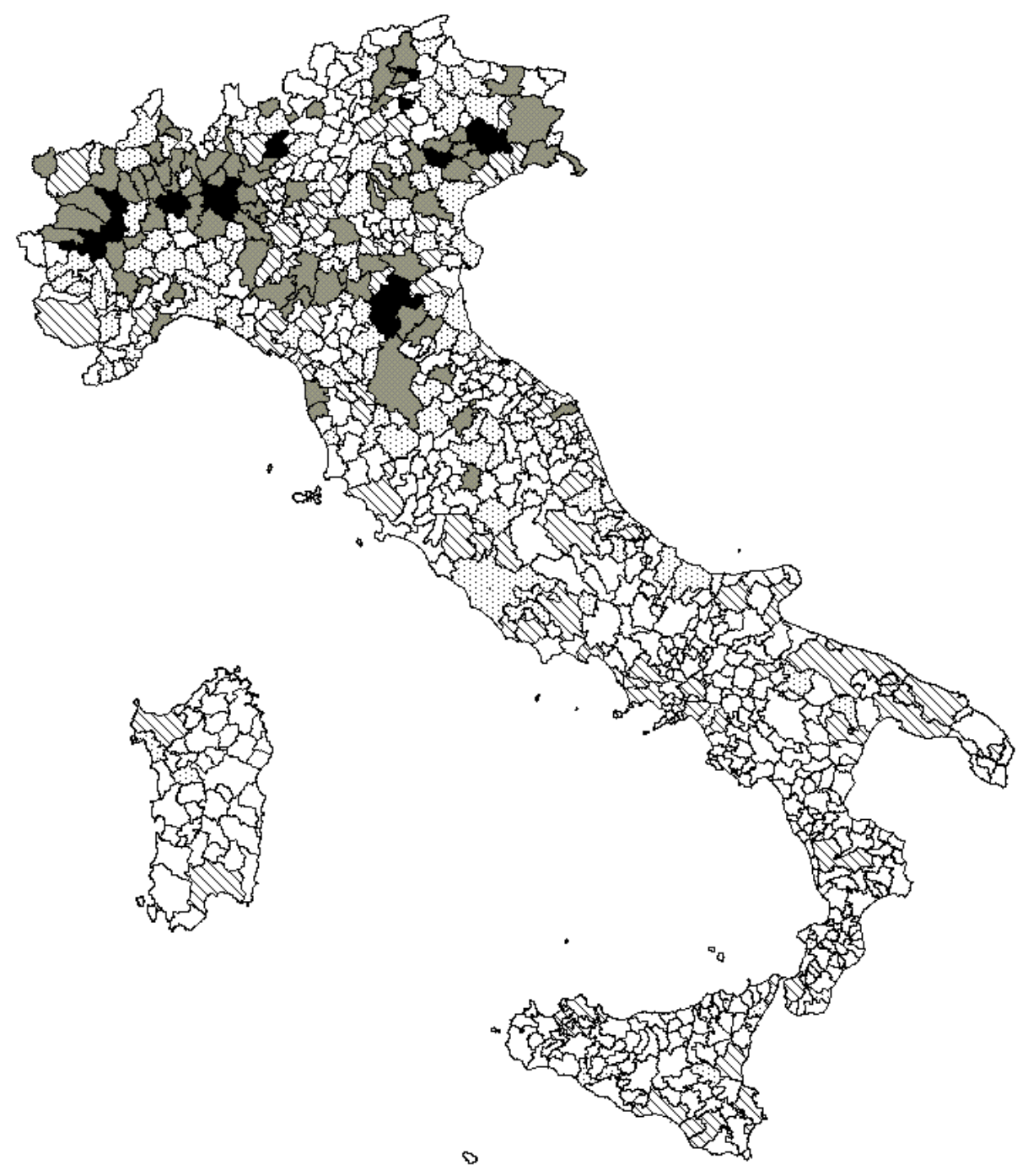

Range (frequence):

$\square_{\theta=0} \mathbf{M N}_{0<\theta<0,5(86)} \because{ }_{0,5 \leq \theta<2} \square_{2 \leq \theta<5} \square_{\theta \geq 5(11)}$ Source: CRENoS patent databank 
Figure 4. Total patents per 100.000 inhabitants (1990-94)

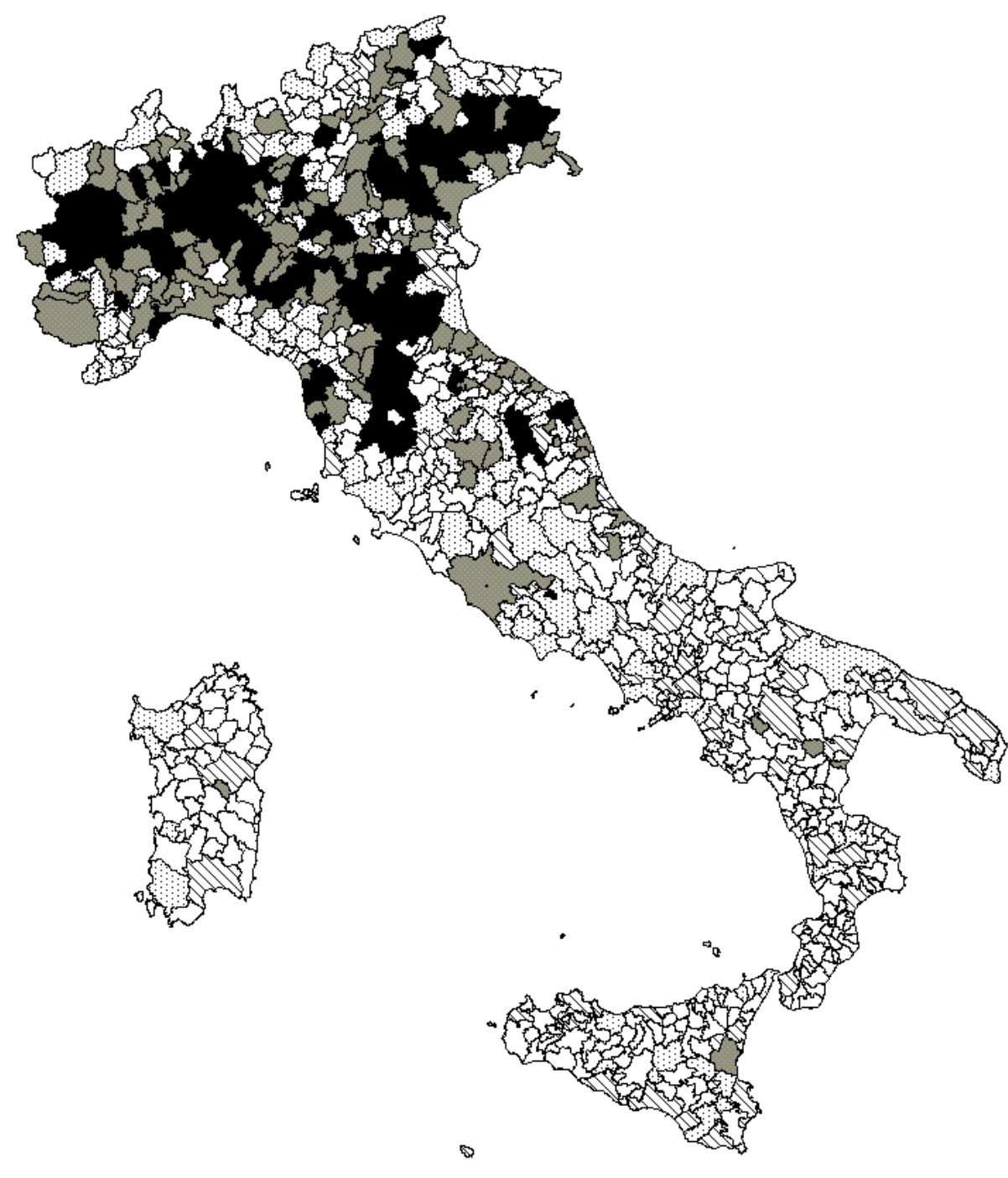

Range (frequence):

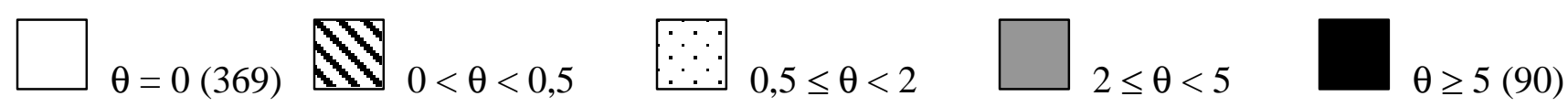

